\title{
Clinical and microbiological epidemiology of Streptococcus pneumoniae bacteraemia
}

\author{
H. MCKENZIE, N. REID and R. S. DIJKHUIZEN*
}

Department of Medical Microbiology and*Infection Unit, University of Aberdeen Medical School, Foresterhill, Aberdeen AB25 2ZD

\begin{abstract}
A survey of Streptococcus pneumoniae bacteraemia in the Grampian region of Scotland was carried out over a 2-year period. One hundred and four bacteraemic episodes were identified in 103 patients, an incidence of 9.8/100000 population/year, and the mortality was $24 \%$. Clinical information was abstracted from 92 sets of patient notes and 98 isolates of $S$. pneumoniae were available for further study. The incidence of $S$. pneumoniae bacteraemia was highest at the extremes of age and peaked at 78 cases/100000 population/year in those over 80 years old. Many patients had predisposing conditions, of which chronic lung disease $(23 \%)$, chronic alcohol abuse $(10 \%)$ and malignant disease $(10 \%)$ were the commonest. Age was the highest risk factor for mortality, with 20 of the 22 deaths in those over 65 years old. The commonest serotype of $S$. pneumoniae isolated was serotype $14(23.5 \%)$. Only one isolate (serotype 6A) showed intermediate resistance to penicillin, but 12 isolates $(12.2 \%)$ were resistant to erythromycin. Nine of these 12 isolates were of serotype 14 and had MICs clustered in the range $12-24 \mathrm{mg} / \mathrm{L}$. Examination of all serotype 14 isolates by pulsed-field gel electrophoresis (PFGE) showed the presence of two distinct genetic clusters, with all the erythromycin-resistant isolates in the same cluster. These isolates had similar PFGE profiles to erythromycin-resistant serotype 14 strains isolated elsewhere in the UK and they were positive for the $m e f E$ gene by PCR, confirming that resistance was of the $M$ phenotype. The recent increase in erythromycin resistance in $S$. pneumoniae may be due, at least in part, to the spread of a serotype 14 clone of the $M$ phenotype which appears to be an important cause of invasive disease.
\end{abstract}

\section{Introduction}

Streptococcus pneumoniae is a major cause of morbidity and mortality worldwide, with invasive infection presenting principally as lobar pneumonia, bacteraemia and meningitis. The average incidence of $S$. pneumoniae bacteraemia in England and Wales between 1989 and 1992 was $8.7 / 100000$ population/year [1] and the mortality of this condition is in the range $16-21 \%$ [2-4]. There are now 90 recognised serotypes of $S$. pneumoniae [5] and the involvement of different serotypes in invasive disease varies between countries and between different age groups within the same country. The most frequently isolated invasive serotypes in recent surveys have included type 1 in Denmark [6], type 3 in Spain and Scotland [7, 8], type

Received 13 Aug. 1999; revised version accepted 1 Sept. 1999.

Corresponding author: Dr H. McKenzie (e-mail:h.mckenzie @abdn.ac.uk).
4 in Ohio, USA [3], type 6 in Switzerland [9] and type 14 in Quebec, Canada and Britain $[10,11]$. The increasing level of antibiotic resistance among $S$. pneumoniae isolates is also of concern [12]. Between 1990 and 1995, full or intermediate resistance to penicillin in England and Wales increased from 1.5\% to $3.9 \%$, while resistance to erythromycin increased from $2.8 \%$ to $8.6 \%$ [13].

Epidemiological surveys are important in order to maintain data on serotype prevalence and levels of antibiotic resistance for $S$. pneumoniae in a particular geographic locality. However, the serotype does not always reflect the genetic relationship between isolates as determined by molecular techniques $[14,15]$. Therefore, a 2-year survey of $S$. pneumoniae bacteraemia was carried out in which selected isolates were characterised by pulsed-field electrophoresis (PFGE) as well as by serotype. MICs for penicillin, cefotaxime and erythromycin were determined by E-test and basic clinical information was obtained for each patient. 


\section{Materials and methods}

\section{Patients}

The study was carried out in a diagnostic microbiology laboratory serving all the hospitals in the Grampian region of Scotland which has a catchment population of 532530. Population estimates for this area at midyear 1994 were available in 4-year age bands from the Registrar-General, Scotland, and were used for calculation of incidence figures. During a 2-year period from 1 Feb. 1993 to 31 Jan. 1995, all patients with a blood culture isolate of $S$. pneumoniae were entered into the study. The age, sex, past medical history, primary site of infection, clinical course and outcome of each patient were abstracted from case notes.

\section{Bacterial strains}

S. pneumoniae isolates were identified by colony morphology on blood agar and sensitivity to optochin. All isolates were serotyped at the Scottish Pneumococcal Reference Laboratory, Stobhill Hospital, Glasgow, by co-agglutination [16]. Susceptibilities to penicillin, cefotaxime and erythromycin were determined by the E-test (AB Biodisk, Sweden) on IsoSensitest Agar (Oxoid) containing lysed horse blood $5 \%$, incubated overnight at $37^{\circ} \mathrm{C}$ in air with $\mathrm{CO}_{2} 5 \%$. Under these conditions, the reference $S$. pneumoniae strain ATTC 49619 had an MIC for erythromycin in the range $0.032-0.25 \mathrm{mg} / \mathrm{L}$, as recommended by the Etest manufacturers. Three erythromycin-resistant serotype 14 strains isolated from cases of meningitis in the south of England between 1990 and 1993 were kindly supplied by Professor B. Spratt, Wellcome Trust Centre for the Epidemiology of Infectious Disease, Oxford. PCR for the mefE gene was performed as described by Sutcliffe et al. [17].

\section{PFGE}

S. pneumoniae isolates were cultured overnight at $37^{\circ} \mathrm{C}$ in air with $\mathrm{CO}_{2} 5 \%$ on two chocolate agar plates and the growth was harvested and washed in suspension buffer (10 mM Tris; $1 \mathrm{M} \mathrm{NaCl})$. The suspension $(300 \mu \mathrm{l})$ was mixed with $200 \mu \mathrm{l}$ InCert agarose (Anachem) 1\% at $45^{\circ} \mathrm{C}$ and $200 \mu \mathrm{l}$ of the mixture were added to each of two insert moulds. The inserts were allowed to set at $4^{\circ} \mathrm{C}$ for $15 \mathrm{~min}$ and then incubated overnight at $37^{\circ} \mathrm{C}$ in $3 \mathrm{ml}$ of lysis buffer $(10 \mathrm{mM}$ Tris; $1 \mathrm{M} \mathrm{NaCl} ; 100 \mathrm{mM}$ EDTA; polyoxyethylene 20 cetyl ether $0.5 \%$; deoxycholate $0.2 \%$; Sarkosyl $0.5 \%$; lysozyme $1 \mathrm{mg} / \mathrm{ml}$ ). The lysis buffer was then discarded and the inserts were placed in a shaking incubator for a further $24 \mathrm{~h}$ at $50^{\circ} \mathrm{C}$ in $3 \mathrm{ml}$ of proteinase buffer $(0.5 \mathrm{M}$ EDTA, $\mathrm{pH} 8.0$; Sarkosyl $0.04 \%$; proteinase $\mathrm{K} 1 \mathrm{mg} / \mathrm{ml})$. After extensive washing in TE buffer (10 mM Tris; $1 \mathrm{mM}$ EDTA, $\mathrm{pH}$ 8.0) inserts were stored at $4^{\circ} \mathrm{C}$.

A piece of each insert was digested overnight at $25^{\circ} \mathrm{C}$ with SmaI (Boehringer-Mannheim) as detailed by the manufacturers. After addition of stop solution (bromophenol blue $0.25 \%$; SDS $0.1 \%$ in TE buffer), the inserts were placed in the wells of an agarose $1 \%$ gel and run for $18 \mathrm{~h}$ on a Digital CHEF gel electrophoresis apparatus (BioRad) with an initial pulse time of $5 \mathrm{~s}$ and a final pulse time of $35 \mathrm{~s}$. The gel was stained with ethidium bromide $0.5 \% \mathrm{v} / \mathrm{v}$ in distilled water and viewed by UV transillumination.

\section{Results}

During the 2-year period, 104 episodes of S. pneumoniae bacteraemia were identified, although this included one patient who had two episodes 12 months apart. Ninety-eight strains of $S$. pneumoniae and 92 patient records were available for further study, although information on age and sex was obtained for all 103 patients. The age-related incidence of $S$. pneumoniae bacteraemia is shown in Fig. 1. The overall mean incidence was 9.8 cases/100000 population/year, but the incidence peaked at the extremes of age with $20 / 100000 /$ year in the $0-4$ age group and $78 /$ $100000 /$ year in those over 80 years old. There were 62 male and 41 female patients, a male:female ratio of $1.5: 1$. There was a seasonal variation in incidence, with most presentations in winter (38\%) and spring (28\%) and fewer cases in autumn (20\%) and summer (14\%).

Recognised predisposing conditions were present in 57 $(62 \%)$ of the 92 patients whose medical records were available for evaluation. These were chronic lung disease $(23 \%)$, chronic alcohol abuse (10\%), malignant disease $(10 \%)$, immunosuppressive therapy $(8 \%)$, diabetes $(6 \%)$, splenectomy $(2 \%)$, renal dialysis $(2 \%)$ and previous head injury $(1 \%)$. The primary sites of infection identified clinically were the lungs (76\%), meninges $(6 \%)$, joints $(2 \%)$ and soft tissues $(1 \%)$, but no site was identified in the remainder $(15 \%)$. The overall mortality rate was $24 \%$, with 15 male and 7 female deaths. Age was the highest risk factor with 20 of the 22 fatal outcomes in patients over 65 years old, a $43 \%$ mortality rate in this age group.

The three most common serotypes isolated were 14 $(23.5 \%), 4(12.2 \%)$ and $23 \mathrm{~F}(9.2 \%)$, with the remaining isolates $(55.1 \%)$ distributed amongst a further 18 serotypes (Fig. 2). Most isolates (93.9\%) belonged to serotypes that are included in the current vaccine, the exceptions being serotypes 23A (two isolates) and $6 \mathrm{~A}$ (four isolates). The two 23A strains came from two separate episodes of bacteraemia in the same patient with an intervening interval of 12 months. The patient was a 74-year-old woman with no known predisposing illness or immune deficit and no obvious source of infection. The mortality associated with individual serotypes is shown in Fig. 2. Serotype 6A (three of four cases) and serotype 19A (three of five cases) infections were both associated with high mortality. 


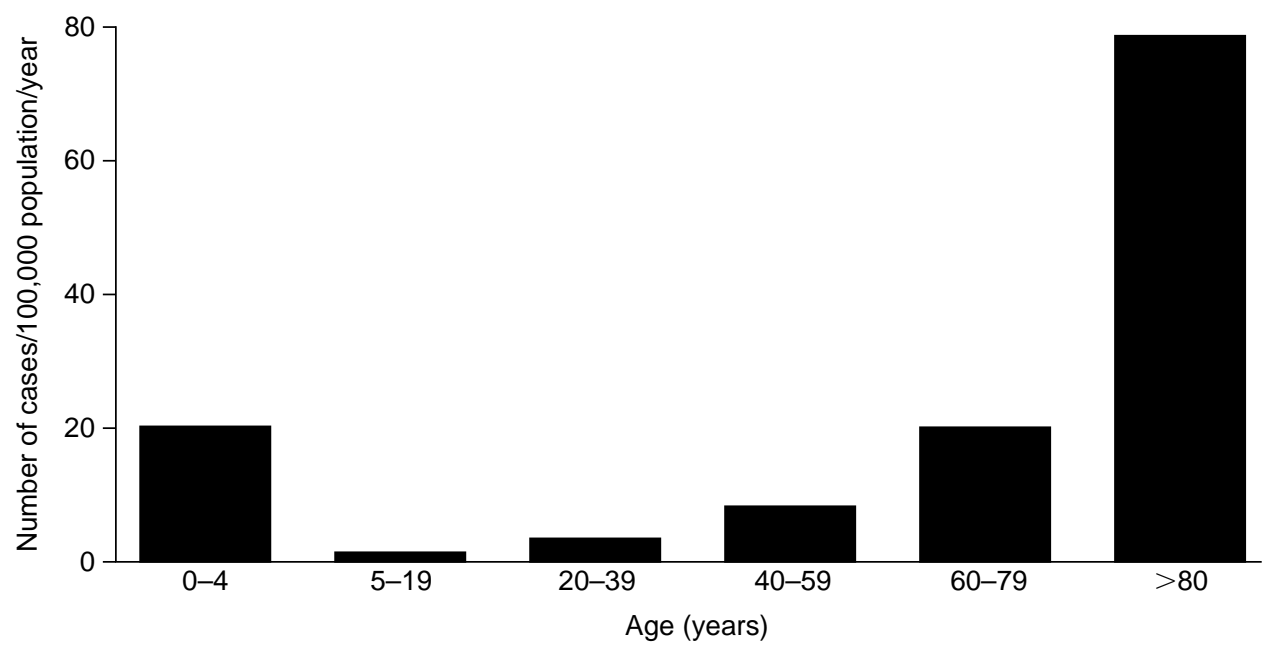

Fig. 1. Annual age-related incidence of S. pneumoniae bacteraemia in the Grampian region of Scotland.

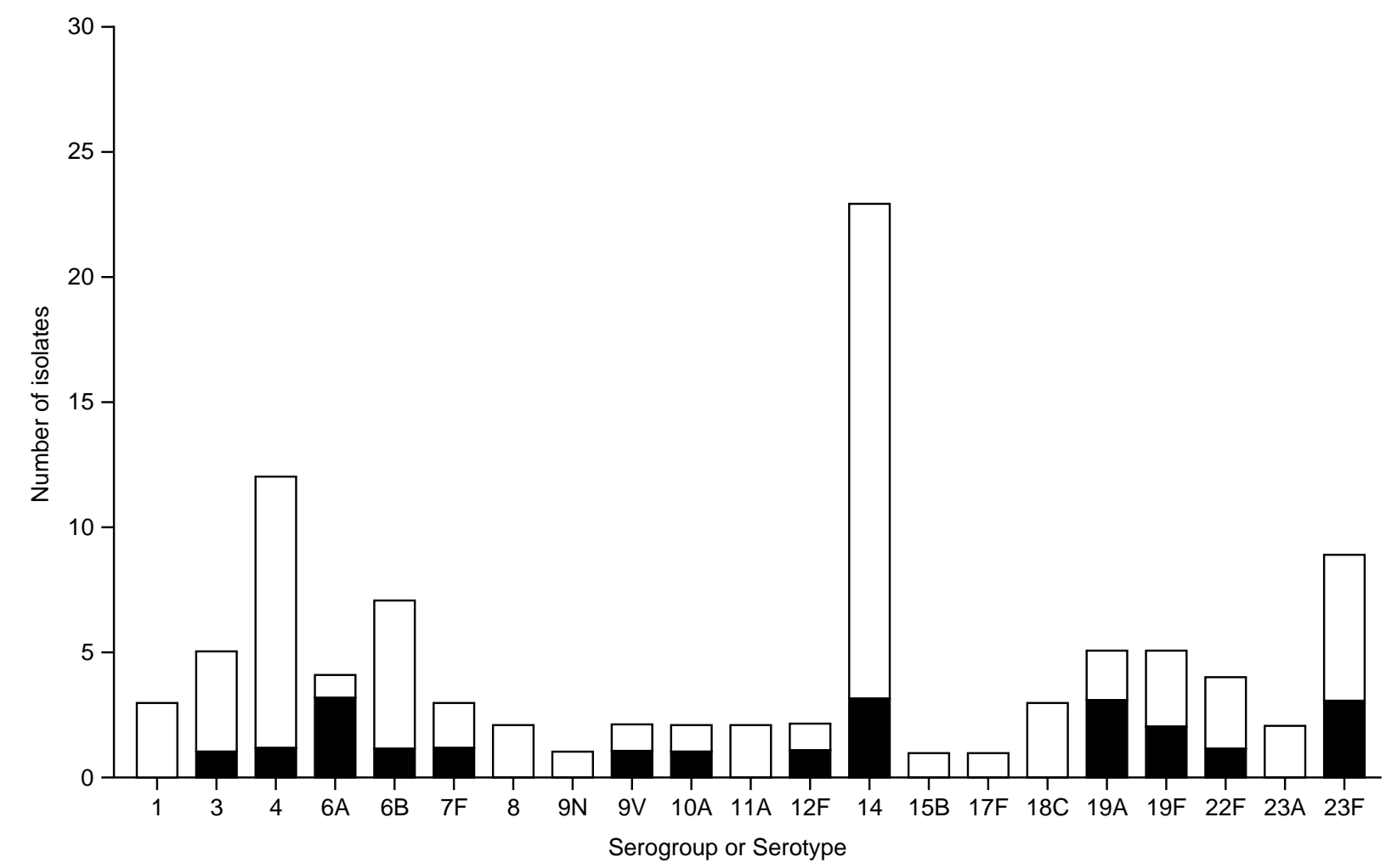

Fig. 2. Distribution of $S$. pneumoniae serogroups or serotypes among 98 isolates and number of fatalities (घ) associated with each.

The antibiotic sensitivities of all 98 isolates are summarised in Table 1. Only one isolate (serotype 6A) showed intermediate resistance to penicillin (MIC $1 \mathrm{mg} / \mathrm{L})$ and the MIC of cefotaxime for this isolate $(0.5 \mathrm{mg} / \mathrm{L})$ was higher than for all other isolates. Resistance to erythromycin (MIC >0.5 mg/L) was detected in $12(12.2 \%)$ of the 98 isolates and the distribution of erythromycin MICs for all isolates is shown in Fig. 3. Nine of the 12 erythromycin-resistant isolates were serotype 14 and these formed a cluster with MICs in the range $12-24 \mathrm{mg} / \mathrm{L}$ (Fig. 3), differentiating them clearly from the other three erythromycin-resistant strains which were in serotypes $11 \mathrm{~A}(\mathrm{MIC} 2 \mathrm{mg} / \mathrm{L}), 18(\mathrm{MIC}>256 \mathrm{mg} / \mathrm{L})$ and $15 \mathrm{~B}$ $(\mathrm{MIC}>256 \mathrm{mg} / \mathrm{L})$.

PFGE of the 23 serotype 14 isolates showed two distinct groupings, each comprising 11 isolates with similar, although not identical band patterns. The remaining isolate had a unique pattern. All nine erythromycin-resistant serotype 14 isolates were in the same PFGE group and examples are shown in Fig. 4 (lanes 4-7). There were two erythromycin-sensitive isolates in this group and one of these is shown (lane 
Table 1. Antibiotic sensitivity test results for 98 strains of $S$. pneumoniae

\begin{tabular}{llccc}
\hline Antibiotic & $\begin{array}{c}\text { MIC range } \\
(\mathrm{mg} / \mathrm{L})\end{array}$ & $\begin{array}{c}\text { MIC50 } \\
(\mathrm{mg} / \mathrm{L})\end{array}$ & $\begin{array}{c}\text { MIC90 } \\
(\mathrm{mg} / \mathrm{L})\end{array}$ & $\begin{array}{c}\text { Number (\%) } \\
\text { of resistant } \\
\text { strains }\end{array}$ \\
\hline Penicillin & $0.002-1$ & 0.016 & 0.023 & $1(1.0)$ \\
Cefotaxime & $0.006-0.5$ & 0.012 & 0.016 & 0 \\
Erythromycin & 0.023 to $>256$ & 0.064 & 12 & $12(12.2)$ \\
\hline
\end{tabular}

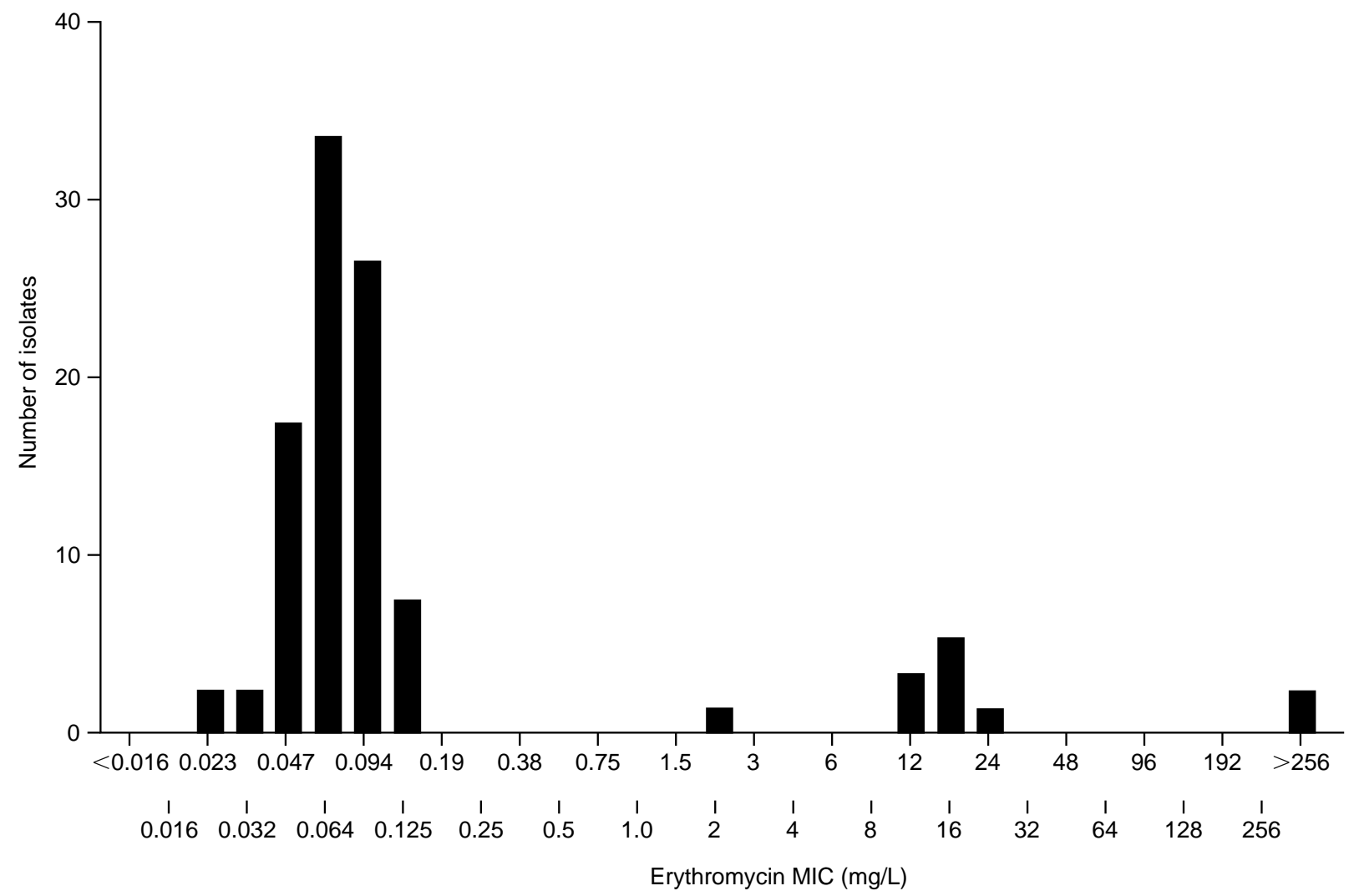

Fig. 3. Distribution of MICs of erythromycin for 98 isolates of S. pneumoniae.

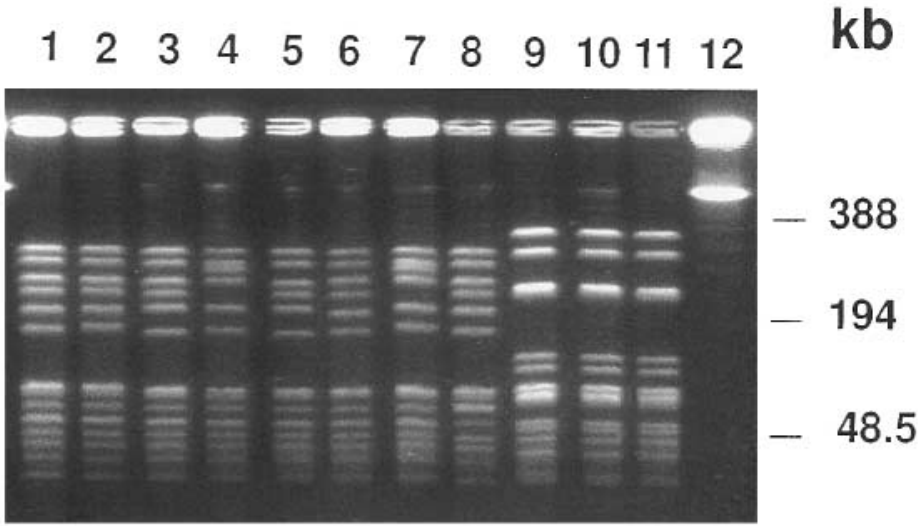

erythromycin $\mathbf{R} R \mathbf{R} R \mathbf{R} R \quad \mathbf{S} S$ S $S$

mefE +++++++

Fig. 4. PFGE of SmaI digests of erythromycin-resistant serotype 14 S. pneumoniae isolates from the South of England (lanes 1-3) and North-East Scotland (4-7), and of erythromycin-sensitive serotype 14 isolates (8-11). The results of erythromycin susceptibility tests and PCR for mef E are shown for each isolate. Lane 12, mol. wt markers. 
8). Three erythromycin-resistant serotype 14 isolates from the south of England had similar PFGE patterns to the resistant isolates from the present study (Fig. 4, lanes 1-3). All isolates in the second serotype 14 PFGE group (examples in lanes 9-11) were erythromycin-sensitive. PCR for the mefE gene was positive for all erythromycin-resistant serotype 14 isolates.

\section{Discussion}

As in previous studies, the highest incidence of pneumococcal bacteraemia occurred during the winter and spring [3] in patients at the extremes of age [6]. The incidence of 9.8 episodes/year/100 000 population in the present study is comparable to the 8.7/ year/100000 reported previously for England and Wales [1]. The mortality of $24 \%$ is higher than that reported in other studies [2-4], but clearly this figure depends upon the demographics of the population studied. The high incidence and mortality of this disease in the elderly is particularly noteworthy and highlights the need to target immunisation towards this group.

Serotype 14 was the predominant serotype in the present study and accounted for $23.5 \%$ of all isolates, compared with a figure of $15.4 \%$ for bacteraemia in Britain between 1982 and 1990 [11]. This serotype was the most prevalent in other studies of invasive disease in Quebec [10], Finland [18] and Connecticut, USA [19]. Penicillin resistance remains relatively uncommon in the UK, but the incidence of $1 \%$ found here is lower than that of 3.9\% reported for England and Wales for 1995 [13]. The incidence of erythromycin resistance in different countries is extremely variable, with estimates ranging from $1.1 \%$ in the USA in 1987 to $51 \%$ in Spain in 1991 [12]. Erythromycin resistance in the UK has increased since 1986 [11] and Johnson et al. [13] recently reported $8.6 \%$ resistance in a survey of mixed clinical isolates in 1995. An association between erythromycin resistance and serotype 14 is well established [11], and other investigators have demonstrated the existence of an erythromycin-resistant clone within serotype 14 in isolates from England and Wales [20]. The present study demonstrates that the clone prevalent in North-East Scotland is similar to isolates from the South of England and it is possible that this clone is responsible for the increase in erythromycin resistance seen in the UK in recent years.

The best described mechanism of resistance to erythromycin in $S$. pneumoniae is associated with the transposon $\operatorname{Tn} 1545$, which characteristically also carries tetracycline resistance [21]. The relevant erm gene on this transposon codes for an enzyme that catalyses methylation of $23 \mathrm{~S}$ rRNA, so that erythromycin no longer binds to its target site [21]. Such strains show constitutive or inducible resistance to clindamycin and are designated as the MLS phenotype. In the more recently described $M$ phenotype, erythromycin resistance is mediated by an efflux mechanism and there is no inducible resistance to clindamycin $[22,23]$. The $m e f E$ gene is associated with $\mathrm{M}$ phenotype resistance [24] and was detected in the nine serotype 14 erythromycin-resistant strains, which were sensitive to clindamycin and tetracycline (data not shown). Therefore the serotype 14 clone exhibits $M$ phenotype resistance.

Jetté et al. [10] found a significantly higher mortality associated with serogroup 19 in adult pneumonia than with other serogroups, but in the present study the sample size was too small to claim statistical significance for the increased mortality apparently associated with serotypes 6A and 19A. However, the high mortality of pneumococcal infection justifies its continued surveillance in respect of serotype or genotype prevalence and antibiotic resistance. Further molecular studies of clinically well-defined strains on a wider geographical basis will allow the possible emergence of antibiotic-resistant or highly pathogenic clones to be monitored.

We acknowledge the help of the Scottish Pneumococcal Reference Laboratory, Stobhill Hospital, Glasgow, for their help with serotyping. In particular we are grateful for the help and support given by the late Dr Les Smart, to whose memory this paper is dedicated. We also acknowledge excellent technical help from Ms J. Skinner and Ms L. Ford.

\section{References}

1. Aszkenasy OM, George RC, Begg NT. Pneumococcal bacteraemia and meningitis in England and Wales 1982 to 1992. Commun Dis Rep CDR Rev 1995; 5: R45-R50.

2. Singh KP, Voolmann T, Lang SD. Pneumococcal bacteraemia in south Auckland: a five year review with emphasis on prescribing practices. NZ Med J 1992; 105: 394-395.

3. Plouffe JF, Moore SK, Davis R, Facklam RR. Serotypes of Streptococcus pneumoniae blood culture isolates from adults in Franklin County, Ohio. J Clin Microbiol 1994; 32: 1606-1607.

4. Kuikka A, Syrjanen J, Renkonen O-V, Valtonen VV. Pneumococcal bacteraemia during a recent decade. J Infect 1992; 24: $157-168$.

5. Henrichsen J. Six newly recognized types of Streptococcus pneumoniae. J Clin Microbiol 1995; 33: 2759-2762.

6. Nielsen SV, Henrichsen J. Incidence of invasive pneumococcal disease and distribution of capsular serotypes of pneumococci in Denmark, 1989-94. Epidemiol Infect 1996; 117: 411-416.

7. Fenoll A, Martin Bourgon C, Munoz R, Vicioso D, Casal J. Serotype distribution and antimicrobial resistance of Streptococcus pneumoniae isolates causing systemic infections in Spain, 1979-1989. Rev Infect Dis 1991; 13: 56-60.

8. Smart LE, Platt DJ, Timbury MC. A comparison of the distribution of pneumococcal types in systemic disease and the upper respiratory tract in adults and children. Epidemiol Infect 1989; 98: 203-209.

9. Wüst J, Huf E, Kayser FH. Antimicrobial susceptibilities and serotypes of invasive Streptococcus pneumoniae strains in Switzerland. J Clin Microbiol 1995; 33: 3159-3163.

10. Jetté LP, Lamothe F and the Pneumococcus Study Group. Surveillance of invasive Streptococcus pneumoniae infection in Quebec, Canada, from 1984 to 1986: serotype distribution, antimicrobial susceptibility and clinical characteristics. J Clin Microbiol 1989; 27:1-5.

11. Colman G, Cooke EM, Cookson BD, Cooper PG, Efstratiou A, George RC. Pneumococci causing invasive disease in Britain 1982-1990. J Med Microbiol 1998; 47: 17-27.

12. Lister PD. Multiply-resistant pneumococcus: therapeutic pro- 
blems in the management of serious infections. Eur $J$ Clin Microbiol Infect Dis 1995; 14 Suppl 1: 18-25.

13. Johnson AP, Speller DCE, George RC, Warner M, Domingue G, Efstratiou A. Prevalence of antibiotic resistance and serotypes in pneumococci in England and Wales: results of observational surveys in 1990 and 1995. BMJ 1996; 312: $1454-1456$

14. Kell CM, Jordens JZ, Daniels M et al. Molecular epidemiology of penicillin-resistant pneumococci isolated in Nairobi, Kenya. Infect Immun 1993; 61: 4382-4391.

15. Lefevre JC, Faucon G, Sicard AM, Gasc AM. DNA fingerprinting of Streptococcus pneumoniae strains by pulsedfield gel electrophoresis. J Clin Microbiol 1993; 31: 27242728.

16. Smart LE. Serotyping of Streptococcus pneumoniae strains by coagglutination. J Clin Pathol 1986; 39: 328-331.

17. Sutcliffe J, Grebe T, Tait-Kamradt A, Wondrack L. Detection of erythromycin-resistant determinants by PCR. Antimicrob Agents Chemother 1996; 40: 2562-2566.

18. Eskola J, Takala AK, Kela E, Pekkanen E, Kalliokoski R, Leinonen M. Epidemiology of invasive pneumococcal infections in children in Finland. JAMA 1992; 268: 3323-3327.

19. Shapiro ED, Austrian R. Serotypes responsible for invasive
Streptococcus pneumoniae infections among children in Connecticut. J Infect Dis 1994; 169: 212-214.

20. Hall LMC, Whiley RA, Duke B, George RC, Efstratiou A. Genetic relatedness within and between serotypes of Streptococcus pneumoniae from the United Kingdom: analysis of multilocus enzyme electrophoresis, pulsed-field gel electrophoresis, and antimicrobial resistance patterns. J Clin Microbiol 1996; 34: 853-859.

21. Clewell DB, Flannagan SE, Jaworski DD. Unconstrained bacterial promiscuity: the $\operatorname{Tn} 916-\operatorname{Tn} 1545$ family of conjugative transposons. Trends Microbiol 1995; 3: 229-236.

22. Sutcliffe J, Tait-Kamradt A, Wondrack L. Streptococcus pneumoniae and Streptococcus pyogenes resistant to macrolides but sensitive to clindamycin: a common resistance pattern mediated by an efflux system. Antimicrob Agents Chemother 1996; 40: 1817-1824.

23. Shortridge VD, Flamm RK, Ramer N, Beyer J, Tanaka SK Novel mechanism of macrolide resistance in Streptococcus pneumoniae. Diagn Microbiol Infect Dis 1996; 26: 73-78

24. Tait-Kamradt A, Clancy J, Cronan M et al. MefE is necessary for erythromycin-resistant M phenotype in Streptococcus pneumoniae. Antmicrob Agents Chemother 1997; 41: 22512255 . 